\title{
Scaling Agile Adoption Motivators from Management Perspective: An Analytical Hierarchy Process Approach
}

\author{
Rooh Ullah Jan $\left(\mathbb{D},{ }^{1}\right.$ Muhammad Usman $\left(\mathbb{D},{ }^{1}\right.$ Muhammad Faisal Abrar $\left(\mathbb{D},{ }^{2}\right.$ Najeeb Ullah $\left(\mathbb{D},{ }^{2}\right.$ \\ Muhammad Asshad $\left(\mathbb{D},{ }^{3}\right.$ and Sikandar Ali $\mathbb{D D}^{3}$ \\ ${ }^{1}$ Department of Computer Software Engineering, University of Engineering \& Technology, Mardan, \\ Khyber Pakhtunkhwa, Pakistan \\ ${ }^{2}$ Department of Computer Science, University of Engineering \& Technology, Mardan, Khyber Pakhtunkhwa, Pakistan \\ ${ }^{3}$ Department of Information Technology, The University of Haripur, Haripur, Khyber Pakhtunkhwa, Pakistan
}

Correspondence should be addressed to Sikandar Ali; sikandar@cup.edu.cn

Received 22 July 2021; Accepted 15 October 2021; Published 31 October 2021

Academic Editor: Cristian Mateos

Copyright (C) 2021 Rooh Ullah Jan et al. This is an open access article distributed under the Creative Commons Attribution License, which permits unrestricted use, distribution, and reproduction in any medium, provided the original work is properly cited.

\begin{abstract}
Agile methodology has been noted as the mostly used method for software development over the past few years. This methodology guarantees the rapid delivery of software products with lower cost and greater customer contentment. The adoption of agile methods was initially applied in the software development industry for single, small project teams following the principles of Agile Manifesto. The intense need of the time is to identify from management perspective the motivators that can be focused on to adopt agile methodologies in large-scale projects. Therefore, the main purpose of the study is to develop from management perspective a priority-based taxonomy of motivators that helps in scaling agile methodologies in large-scale projects. The taxonomy is developed in two steps. In the first step, data are collected from a survey and open literature. In the second step, the analytical hierarchy process (AHP) is implemented on the collected data that produced the proposed priority-based taxonomy of the motivators. With the help of AHP model, the 21 motivators of successful project management are categorized into four main categories, i.e., "organization management," "team," "customer and technology," and "process." Furthermore, the AHP analysis is used to rank the motivators and their respective categories in order of their importance. The findings of this study are further reviewed and validated by the agile experts in other organizations. The proposed priority-based taxonomy of motivators can be used as a handbook that gives guidelines on scalability of agile methodologies to large projects, which helps in successful management of large-scale projects.
\end{abstract}

\section{Introduction}

Agile methodology was intended for adopting in solo or small-scale developmental team following the Agile Manifesto $[1,2]$. However, because of the need to be faster in response to market conditions and more flexible, many organizations are adopting agile motivators [3] and applying the principles from the agile software development methodology for larger teams in organizations $[4,5]$.

Applying agile methodologies to large-scale teams and projects [6] is challenging compared to small-scale teams and projects which is the first priority; larger ones will need more harmonization. Large-scale agile development (LSAD) groups and projects demand the participation of further nonagile organizational units. Regardless of these conspicuous issues associated with LSAD groups and projects, an inclination has been observed towards adopting them [7-9]. An in-depth literature review entrenched earlier description of what large-scale agile is [10]. Size was calculated as the number of persons or teams, length of code (lines of code), and project cost. According to [11], a large-scale project would be comprised of forty people and seven development teams. However, [12] argued that a project would be named as large-scale project if it cost more than 10 million GBP and had 50 persons. Moreover, [13] proposed that a project whose lines of code were more than 5 million would be 
named as large-scale project. In [14] perspective, a venture spell of two years having a project scope of 60 to 80 qualities would be assumed as large-scale project. According to [10], through working together and number of coordinating groups, we can quantify project size. The authors stated that a project having 2-9 working together groups would be named as large-scale project and a project with more than ten working together groups would be assumed to be very large-scale one. Apart from the aforementioned findings of various researchers, we found various studies discussing LSAD teams and projects as well. The majority debated the count of persons participating in project. In addition, other researchers such as [15] have stated that agile projects comprised of 50 persons are declared as small, while projects comprised of 50 to 100 persons are declared as large [16]. Members taking part in a workshop named XP 2014 (largescale agile) gave various meanings to LSAD teams [7]. According to them, what is to be considered as large-scale mostly depends upon the person who is defining it and on the circumstances. According to earlier findings of literature, we give the description large-scale to software development organizations (SDOs) comprising around fifty persons or containing a minimum of six development teams. In addition, it is not essential that each employee is a developer; however, it is essential that they belong to the same software development organization. Moreover, they shall be functioning on a similar project or building common product, and in this way they must need to team up. For instance, to assess the organization size, Scrum experts and software architects are the accessible tools.

Furthermore, agile methodology also concentrates on business and management activities. An organization needs to embrace feature-centric and iterative model. They should abandon life-cycle models [17], which needs an adjustment in mentality. Attention must be embraced to short-term project level planning from tolerate organization level [18]. According to agile methodology, the planning process is beneficial for upcoming future [19]. However, lack of planning may be a matter of concern, because corporate customer relationships are frequently built on the implementation of long-term organizational plans. Performing a function through short-term planning requires mingling speculators and examining the way of contracting [20].

Moreover, the priority-based taxonomy of the established motivators is developed using the AHP, one of the most useful methods for solving complex decision problems. Saaty developed this method in 1980 as a tool to solve technical and managerial problems [21]. It aims to quantify relative priorities for a given set of alternatives on a scale of ratios, based on the decision-maker's judgment, and emphasizes the importance of an intuitive decision-maker's judgment and the consistency of comparing alternatives within the decision-making process. Since the decisionmaker relies on knowledge and experience, decisions are made accordingly; the AHP approach corresponds well with the behavior of the decision-maker. The strength of such an approach is the systematic organization of tangible and intangible factors, and it offers a structured but relatively simple solution to the decision-making problems [22].
Moreover, by decomposing a problem in a logical way from the biggest, descending in progressive steps, to the smallest, one is able to link, by simple paired comparison judgments, the little ones to the big ones. The AHP method is highly suitable for areas where intuition, rationality, and irrationality in relation to risk and uncertainty may be found. The problem may include large amounts of social, political, economic, and technical costs with various objectives, criteria, and opportunities. It is used to prioritize (in our case the importance of motivators for adopting agile methodology from a management point of view) and to make appropriate choices. It separates complex problems at the level of pairwise comparisons and then merges again the results that lead to the best rational solution. The AHP method remains the most widespread and widely used theory for decision-making [23]. The AHP is particularly suited to the evaluation of complex multiparameter opportunities with the inclusion of subjective criteria. Following are the key steps of AHP method application.

The first stage of the method is the development of the hierarchy of criteria. The highest tier is the goal or purpose of the decision-making problem. To structure the criteria of a problem is to construct a hierarchy of criteria and subcriteria. Structuring the criteria into subcriteria assists in prioritization. The hierarchy of criteria takes into account the organization's strategy structure and key performance indicators and offers the possibility of selecting the motivator according to its alignment with the business goal. The first challenge is to choose from strategically significant motivators for the organization to establish appropriate and clear criteria. It is also the responsibility of the functional heads of marketing, finance, ICT, sales, and other areas. In selecting criteria, it is almost immediately clear that they are not equally important and that they are interrelated. The second stage is to assign weights to the previously selected criteria and, if required, divide the overall weight of the criteria between the subcriteria. Mian and Dai [24] recommend the paired comparison method for weighting, whereby each criterion is compared with all other criteria. This comparison is carried out in pairs at all hierarchical levels (comparison of two elements belonging to the same group within a hierarchy) and for each level of the entire hierarchy. This allows us to concentrate on only two of the criteria at the time. That way, we can determine for each combination which criteria are more important, which criteria are less important, and how different is their significance.

How can criteria be given weight? Two criteria are generally compared together, and points between 1 and 9 are used. The limitation of scale is the consequence of the realization that the human mind can properly feel and consider just a few elements at a time. In each pair, we assign the degree to the dominant one. The exceptional supremacy of one criterion over the other may be assessed at 9, equality at 1. If the second motivator is of more importance than the first, then we enter the reciprocal value. Thus, we get the values in the field from $1 / 9$ to 9 . This evaluation model is empirically confirmed as being accurate enough for most problems. A greater variety of judgments would reduce the 
symmetry of evaluations. When completing the final assessment, we use the weighted average procedure. This may be achieved by multiplying the size of the criteria and the level of uncertainty.

Several existing studies used AHP methodology to address complicated decision-making problems in manufacturing enterprises, policies management, and many other domains, such as ranking of crucial success factors for software projects, selection and evaluation of clinical engineering and health technology projects, choosing agile software development elements, and selection and assessment of projects in mechanical engineering field. Hence, the importance of AHP approach adoption in various other areas has encouraged us to use it to develop a taxonomy of agile adoption motivators according to their priority ranking.

\section{Related Work}

In 2007, first version of agile survey was conducted [25]. The survey $[25,26]$ demonstrates that a sizable number of software organizations have embraced or are planning to implement agile approaches in a large-scale context. The agile methodology might be considered as a replacement for traditional software development methodologies. Traditional approaches and methodologies emphasize straightforward planning and strict change control, while ASDM adopt changes rapidly $[19,27]$. Research has manifested that accepting change appears to be a feature of both failure and success [20]. It has been established that agile methodologies have boosted client and vendor trust. However, there is evidence that ASDM may not be the ideal choice for larger projects and teams [6]. As a result, one possible solution is that each team seeks its own ASDM balance [20]. Most common agile approaches are Scrum and Extreme Programming (XP) [28]. The difficulty of adopting ASDM grows in proportion to the size of the development team [29]. The problem is partly due to the fact that in an organization there is lack of management change activities [30]. ASDM are not modeled for the use of specific tools or trials, but reasonably on the basis of general and widely accepted approach. Adopting ASDM needs modification of the whole organizational structure [18]. A notable difference between large-scale and small-scale adoption is that large companies rely more on teams and project management. This increases the requirement for strict documentation and hence weakens swiftness and dynamism [31]. Furthermore, for development team collaboration, other nonagile administrative divisions must collaborate. For example, a human resources department may require and compel people to clearly declare their title role in projects [4], or a change control board may ban the usage of repackages on a regular basis [31]. All units affected by the shift to agility must be contacted and discussed, and they must be familiarized with the agile process based on their needs $[4,19,31]$.

ASDM also upset business and management responsibilities. Moving towards iterative and feature-centric models (i.e., deviating from life-cycle models [17], which requires method modification) is an important challenge in managing organizations. The emphasis has to be adopted from long-lasting organization level planning to short-term project level planning [19]. According to ASDM, planning is only beneficial in the short-term projects [19]. Nonetheless, the absence of planning could be a cause for concern, as long-term business customer relationships are generally built on the implementation of long-term organizational plans. Combining business and management activities with short-term planning requires socializing investors and analyzing the contracting process [4]. The industry practitioners at XP2010 [31] chose to create a backlog of issues that they believe should be researched. Agile and large development teams were voted the top hot research subjects by practitioners. Considering the significance of ASDM and large-scale projects and teams, Abrar et al. [3] identified from management perspective the successful project management attributes that can be focused on to adopt agile methodologies for large-scale projects and teams. In this paper, we aim to construct a prioritized taxonomy of the identified project management attributes using the analytical hierarchy process (AHP) approach. Several existing studies apply the AHP approach to solve complicated decisionmaking problems in production houses, managerial policies, and other fields. For example, Rahman et al. [32] proposed a multicriteria decision-making model for application maintenance offshoring using AHP. Akbar et al. [33] conducted a systematic literature review and then performed industrial survey to validate the results. They identified a total of 25 challenges regarding requirement change management based global software development. Using the AHP approach, the challenges were prioritized. Khan and Shameem [34] proposed a multicriteria decision-making taxonomy for development and operations challenging factors using AHP approach. Sayed et al. [35] developed an AHP-based strategy for choosing an appropriate agile method based on the project's needs and nature. Dynamic requirements, requirement modifications, development team, and communication were all used as criteria. Wong and $\mathrm{Li}$ [36] used AHP for the selection of intelligent building systems. Yaghoobi [37] presented a model for prioritizing key success factors of software projects using Fuzzy AHP model. Shameem et al. [38] used AHP for selection of agile software development factors. Sloane et al. [39] performed AHP for clinical engineering and health technology projects assessment. Palcic and Lalic [40] used AHP for the selection and evaluation of project in mechanical engineering. Wen-Ying [41] implemented AHP for risk analysis and management of engineering projects. Therefore, the significance of using AHP approach in different domains motivated us to implement it for developing a taxonomy of the successful project management attributes based on their prioritization for the adoption of ASDM at large-scale development team and project from managers' perspective.

\section{Research Goal}

Applying Agile Software Development Methodologies (ASDM) in large-scale projects is considered difficult as compared to small projects. The fact is that the manifesto of 
ASDM has developed for small projects in terms of project management. In order to apply ASDM to large-scale projects, guidelines need to be developed especially for management perspective. Therefore, the goal of our research is to propose guidelines that guide the scalability of ASDM to large software development projects. Hence, the potential managers of large-scale agile development (LSAD) teams can use the proposed guidelines as handbook for adoption of ASDM. Abrar et al. [3] have identified a total of 21 factors [termed as motivators] for successful management of software development project.

Herein, we summarize the goal and introduce the research questions that derive this study using the GQM [42] template (see Table 1).

We describe the research questions and metrics that complete the GQM as follows:

(1) How could the identified motivators be prioritized for successful management of large-scale software development project using AHP approach?

(2) What would be the taxonomy of the identified motivators that could assist towards the successful adoption of ASDM at large-scale project?

\section{Research Methodology}

The study's main goal is to evaluate motivators and their clusters and establish a priority-based taxonomy, which is accomplished using the research approach depicted in Figure 1. There are two phases of the proposed research methodology: categorization of agile adoption motivators (Section 4.1) and application of the analytical hierarchy process for the development of the priority-based taxonomy (Section 4.2).

In this study, the AHP technique is used in decisionmaking and determines the relevance among several motivators [43]. We used the AHP to prioritize the motivators based on their level of criticality and their respective categories.

4.1. Phase 1: Categorization of Agile Adoption Motivators. In this phase, agile adoption motivators are extracted from a previous study [3]. A team comprising agile practitioners and researchers was established to help in the mapping/ categorization of these motivators. They have extensive knowledge of qualitative software engineering research. An initial online mapping questionnaire was developed and distributed among experts. The purpose of the questionnaire is to validate the motivators and assign them to their respective category. We also ensure that all data obtained from the participants will be used solely for research purposes and will never be shared with anyone else, under any circumstances.

4.2. Phase 2: Application of Analytical Hierarchy Process. The analytical hierarchy process is used to rank the listed motivators and their respective categories. Saaty [44] developed the AHP methodology, which is a common multicriteria decision-making technique. For ranking and prioritizing the listed motivators, it is typically a precise and accurate process. As a result, the traditional AHP methodology is better suited to the analysis of data obtained via the survey process. Furthermore, AHP has been used in a variety of other research domains to solve difficult decisionmaking problems. Shameem et al., for example, [38], used the AHP technique to rank the challenging aspects of agile development process.

Figure 2 shows the steps involved in the implementation of the AHP approach.

The complex decision-making problem is broken down into a hierarchical structure comprising related decision components $[38,40,41]$. The problem is divided into at least three stages by its hierarchical structure. The goal of the problem is presented at the top of the hierarchical structure, which is shown in Figure 3, while the factors and subfactors are classified at levels 2 and 3 .

4.2.1. Step 1: Define the Goal. The main goal of this study is to rank and prioritize the motivators that encourage agile adoption from management perspective in large-scale agile development.

\subsubsection{Step 2: Classify the Categories and Their Corresponding} Motivators. In this step, motivators are mapped to their respective categories through experts.

Step 2 (a): An online questionnaire survey was developed; it contains all the motivators and categories which are evaluated through agile experts to be mapped according to their relevance.

Step 2 (b): The questionnaire survey was distributed online by e-mail and on various social media channels, including LinkedIn, Research Gate, and Facebook. The process of data collection started in Oct 2020 and continued till Dec 2020. Software developers, software analysts, quality assurance engineers, project managers, requirement engineers, researchers, and management experts are among those who responded to the survey.

4.2.3. Step 3: Construct Pairwise Questionnaire Survey. Participants in the initial survey were approached to participate in pairwise comparison survey, which was conducted in order to perform AHP technique to prioritize motivators and their respective categories. 49 out of 57 respondents responded positively and were willing to participate in the pairwise comparison survey. Information was gathered from 49 survey participants, and this small sample may threaten the study's findings and conclusions; however, Analytical Hierarchy Process is a subjective method that can handle small samples of data [38]. Furthermore, different research studies have implemented the Analytical Hierarchy Approach with a relatively small size of sample data. For example, Shameem et al. [38] gathered data from five participants and evaluated it based on their perceptions and 
TABLE 1: Goal question metric model.

\begin{tabular}{lc}
\hline Object of the study & Developing guidelines (in terms of the taxonomy level) \\
\hline $\begin{array}{l}\text { Purpose } \\
\text { Focus }\end{array}$ & Prioritizing the motivators \\
$\begin{array}{l}\text { Stakeholders } \\
\text { Context }\end{array}$ & Adoption of agile software development methodology (ASDM) for large-scale development teams \\
Project managers' perspective & Scaling ASDM
\end{tabular}
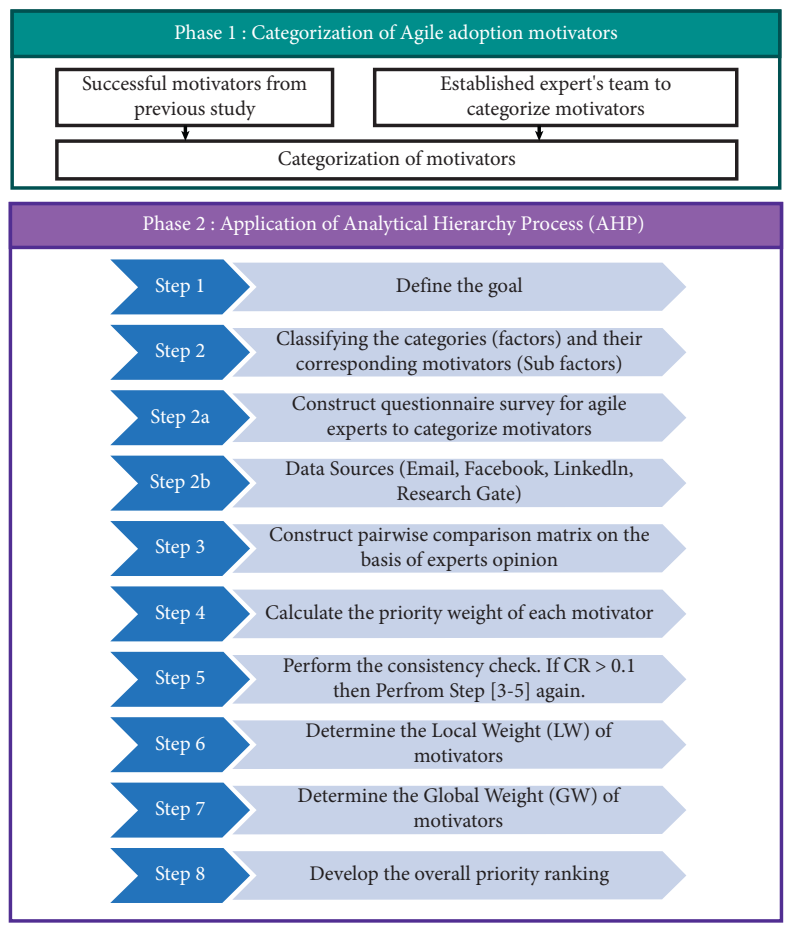

FIGURE 1: Phases of the research methodology.

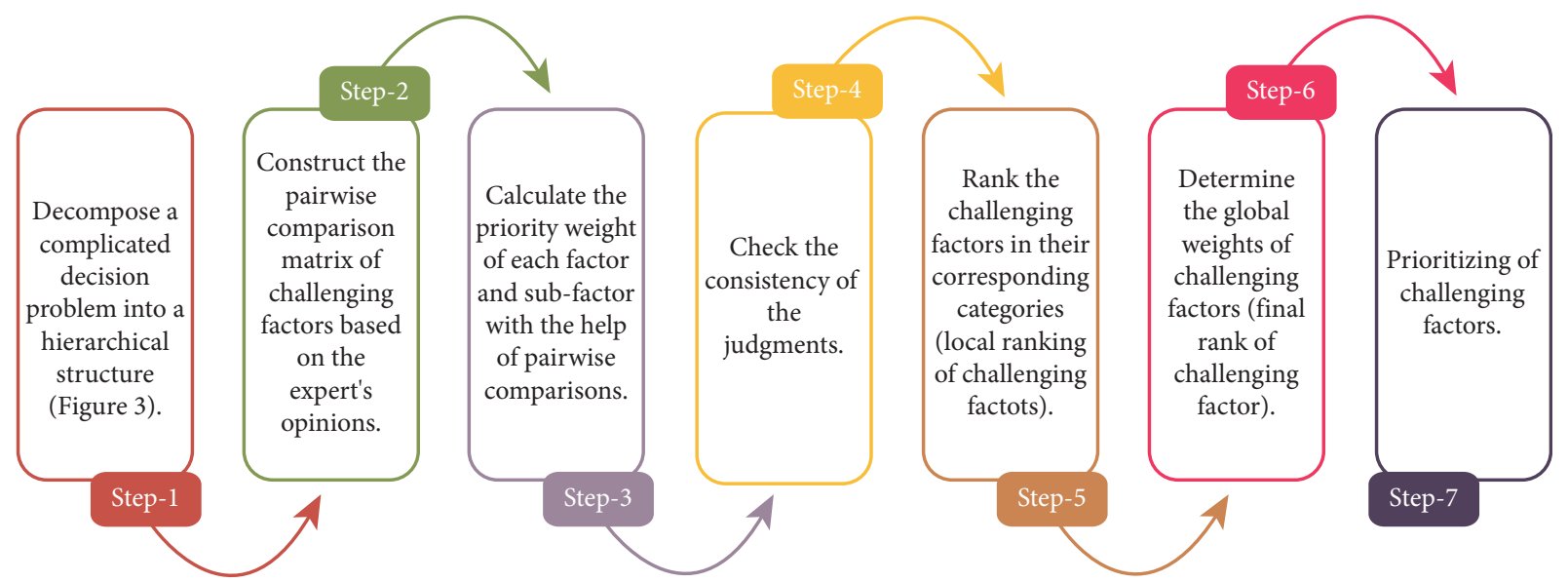

Figure 2: Analytical Hierarchy Process (AHP) stages.

experiences. Cheng and $\mathrm{Li}$ [45] received data from nine experts to help them prioritize factors that could influence the construction partnership process. Furthermore, Wong and $\mathrm{Li}$ [36] used AHP to pick intelligent building systems based on the participation of nine experts in a survey. As a result of the discussion above, the given sample size (49 responses) appears to be adequate for evaluating the data collected for the AHP.

The pair comparison is then explained by comparing two motivators, i.e., M1 and M2, regarding their importance for 


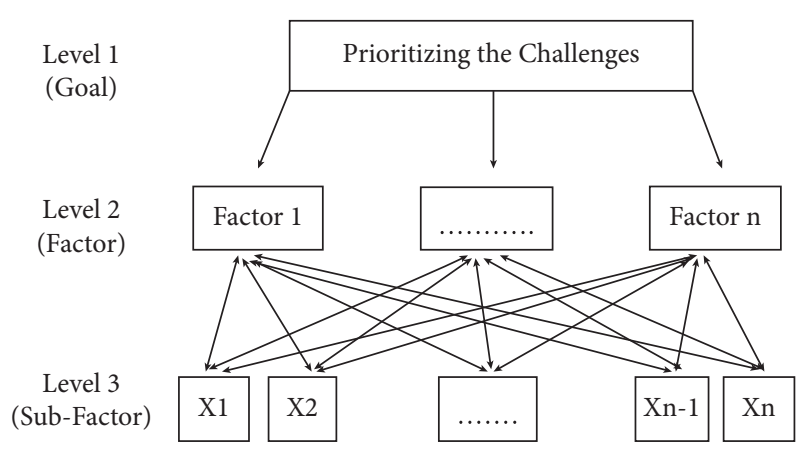

FIgURE 3: Hierarchal structure of decision problem.

agile adoption from management perspective. M2 is $1 / 5$ with respect to M1 because $\mathrm{M} 1$ has a five-degree greater value than M2 (Table 2).

In Section 5.3, we used the same method to construct pairwise comparison matrices for all of the listed motivators and their respective categories. To assess the importance of the motivators and their respective categories, we used a 9point standardized comparison scale (Table 3).

4.2.4. Step 4: Calculate the Priority Weight of Each Motivator. A pairwise comparison of the motivators and their respective categories is performed to determine their priority weights [41]. At each level, motivators are compared based on their degree of relative importance and the criteria established at the upper level.

The priority weight is determined using the pairwise comparison matrices as follows:

(i) Matrix: pairwise comparison matrix of the motivators.

(ii) Normalizing the matrix: divide each value in each column by the sum of that column.

(iii) Priority weight: compute average for each normalization matrix row.

4.2.5. Step 5: Perform the Consistency Check. According to Shameem et al. [38] the consistency index (CI) and consistency ratio (CR) can be used to calculate the consistency of the pairwise comparison matrix in the AHP, as demonstrated in the following equations:

$$
\begin{aligned}
& \text { Consistency index }(\mathrm{CI})=\frac{\left(\lambda_{\max }-n\right)}{(n-1)}, \\
& \text { Consistency ratio }(\mathrm{CR})=\frac{\mathrm{CI}}{\mathrm{RI}} .
\end{aligned}
$$

The $\lambda_{\max }$ value is the highest eigenvalue which can be computed by multiplying the given priority weight $(W)$ by the sum of each column in the comparison matrix (Section 5.3 ), and $n$ refers to the total number of factors in the given pair comparison matrix. As it can be seen in consistency ratio, RI represents random index and its value changes depending on the size of matrix (Table 4).
TABLE 2: Example of pairwise comparison matrix.

\begin{tabular}{lcc}
\hline S. no. & M1 & M2 \\
\hline M1 & 1 & 5 \\
M2 & $1 / 5$ & 1 \\
\hline
\end{tabular}

Table 3: Details of the intensity scale.

\begin{tabular}{lc}
\hline Description & Significance intensity \\
\hline Equally important & 1 \\
Moderately important & 3 \\
Strongly more important & 5 \\
Very strongly more important & 7 \\
Extremely more important & 9 \\
Intermediate values & $2,4,6,8$ \\
\hline
\end{tabular}

TABLE 4: Random index value relative to matrix size.

\begin{tabular}{lcccccccccc}
\hline Size of matrix & 1 & 2 & 3 & 4 & 5 & 6 & 7 & 8 & 9 & 10 \\
\hline RI & 0 & 0 & 0.58 & 0.9 & 1.12 & 1.24 & 1.32 & 1.41 & 1.45 & 1.49
\end{tabular}

The acceptable consistency ratio value is up to 0.1 , and the priority factor is acceptable only when the CR value is less than 0.1 . If the $\mathrm{CR}$ value is not within the appropriate range, the procedure should be repeated to improve consistency. Section 5.3 of this study contains the estimated CR values for each comparison matrix.

\subsubsection{Step 6: Determine the Local Weight (LW) of Motivators.} Priority weight for each motivator in its respective category is called the local weight of motivator. Therefore, all the priority weights of motivators with respect to their categories are determined and listed in this step.

4.2.7. Step 7: Determine the Global Weight (GW) of Motivators. The value of global weight of each motivator is determined by the value of local weight within each category multiplied by the value of local weight of its respective category.

4.2.8. Step 8: Develop the Overall Priority Ranking. In this step, the final list of priority for agile adoption motivators is determined, which is based on each motivator's global weight. Motivators having higher global weight value in all categories are considered high ranked.

\section{Findings}

5.1. Motivators Extracted from Previous Study. Abrar et al. [3] identified a total of 21 critical motivators for large-scale agile adoption from management point of view, which are listed in Table 5. Each Motivator is given a unique identity in this study, i.e., $M 1, M 2, \ldots$, etc.

5.2. Responses of Survey Variables. Participants have completed the initial mapping questionnaire survey that is conducted for the implementation of AHP approach to 
TABLE 5: List of motivators.

\begin{tabular}{lc}
\hline S. no. & Motivators/attributes \\
\hline M1 & Strong executive support \\
M2 & Cooperative organizational culture \\
M3 & Face to face meetings \\
M4 & Dedicated management \\
M5 & Team competency in agile development expertise \\
M6 & Agile development environment \\
M7 & Team encouragement \\
M8 & Customer satisfaction \\
M9 & Strong collaboration with customer \\
M10 & Sustainable planning \\
M11 & Use of automated software tools \\
M12 & Scheduled training for team members \\
M13 & Strong collaboration and communications \\
M14 & Risk management \\
M15 & Knowledge sharing management \\
M16 & Quality production using pair programming \\
M17 & Mechanism for change management \\
M18 & Leadership strong commitment and team autonomy \\
M19 & Pilot project in case of no experience \\
M20 & Training, learning, and briefing of top management on agile \\
M21 & Requirements management using agile-oriented requirement management process \\
\hline
\end{tabular}

prioritize motivators and their respective categories. The mapping team is composed of author as well as 23 external experts. External experts involved in the assessment of mapping process have expertise in agile methodology. Their level of experience as well as their positions is shown in Table 6. The purpose of this mapping process is to evaluate motivators with respect to their key categories and provide a framework based on experts' opinion. The motivators were classified into their relevant categories by experts of the mapping team who participated in the mapping process.

5.3. Application of Analytical Hierarchy Process. In this section, we determined the priority of motivators over their particular categories and all other categories using AHP methodology. Furthermore, each category is also prioritized using AHP approach. The key milestones of the AHP approach are briefly addressed in Section 4.2 and followed as below.

5.3.1. Step 1: Define the Goal. The goal is to rank and prioritize the agile adoption motivators from management perspective in LSAD.

\subsubsection{Step 2. Classify the Categories and Their Corresponding} Motivators. The motivators listed in Table 5 were further categorized based on Shameem et al.'s [38] framework. Shameem et al. [38] have categorized agile development process attributes into "organization management," "process," "team," and "customer and technology." Since both studies have been conducted on the agile development model, we used the same framework. The motivators are classified into the above-mentioned four categories. Figure 4 shows the mapping of each motivators to its respective category according to experts' point of view. The organization management category comprises "strong executive support," "dedicated management," "risk management," "knowledge sharing management," and "mechanism for change management." The Process category comprises "sustainable planning," "strong collaboration and communication," "quality production using pair programming," "pilot project in case of no experience," "training, learning, and briefing of top management on agile," and "requirements management using agile-oriented requirement management process." The customer and technology category comprises "face to face meetings," "agile development environment," "customer satisfaction," "strong collaboration with customer," and "use of automated software tools." The team category comprises "cooperative organization culture," "team competency in agile development expertise," "team encouragement," "scheduled training for team members," and "leadership strong commitment and team autonomy."

Based upon categorization illustrated in Figure 4, we developed a hierarchical structure as shown in Figure 5. It depicts the mapping of motivators to their relative category based upon experts' opinion, where first level depicts the goal of the study, while level two depicts the motivators (factors) and level three depicts the categories (subfactors).

5.3.3. Step 3. Calculate the Prioritization Weight by Developing a Pairwise Comparison Matrix. The pairwise comparison matrix is used to evaluate the weights of motivators in this step. Based on information gathered during the fourcategory classification of motivators, the pairwise matrix is established for each category and its respective motivators. Tables 7-14 provide full descriptions of the pairwise comparison for each group ("organization management," "team," "process," and "customer and technology"). Tables 15 and 16 represent the outcomes of the categories' pairwise comparison. 
TABLE 6: Survey respondent's information.

\begin{tabular}{|c|c|c|c|c|}
\hline S. no. & Job title & Country & Industry experience & Working experience in agile process \\
\hline 1 & Software developer & Pakistan & 8 & 3 \\
\hline 2 & Web developer & Pakistan & 5 & 4 \\
\hline 3 & Software developer & Pakistan & 5 & 5 \\
\hline 4 & Research assistant & China & 3 & 3 \\
\hline 5 & Lecturer & Pakistan & 7 & 3 \\
\hline 6 & Lecturer & Pakistan & 6 & 4 \\
\hline 7 & IT incharge & Italy & 3 & 3 \\
\hline 8 & Software developer & Sweden & 2 & 2 \\
\hline 9 & $\mathrm{CEO}$ & USA & 20 & 10 \\
\hline 10 & Software manager & Pakistan & 12 & 7 \\
\hline 11 & Software tester & Pakistan & 6 & 6 \\
\hline 12 & IT director & Pakistan & 18 & 8 \\
\hline 13 & Researcher & Pakistan & 7 & 5 \\
\hline 14 & Professor & Pakistan & 9 & 6 \\
\hline 15 & Software developer & Pakistan & 8 & 8 \\
\hline 16 & Research associate & China & 6 & 6 \\
\hline 17 & Senior software developer & Pakistan & 10 & 7 \\
\hline 18 & Web developer & Pakistan & 4 & 4 \\
\hline 19 & Junior software developer & Pakistan & 5 & 5 \\
\hline 20 & Software engineer & Pakistan & 4 & 3 \\
\hline 21 & Software tester & Pakistan & 4 & 3 \\
\hline 22 & Software developer & Pakistan & 2 & 2 \\
\hline 23 & Software developer & Pakistan & 3 & 3 \\
\hline 24 & Web engineer & Pakistan & 7 & 6 \\
\hline 25 & IT team lead & Pakistan & 9 & 8 \\
\hline 26 & Researcher & Germany & 8 & 5 \\
\hline 27 & Project manager & Pakistan & 13 & 7 \\
\hline 28 & Project manager & Pakistan & 10 & 8 \\
\hline 29 & Lecturer & Pakistan & 10 & 6 \\
\hline 30 & Web developer & Pakistan & 7 & 5 \\
\hline 31 & Web developer & Pakistan & 6 & 6 \\
\hline 32 & Software engineer & Pakistan & 3 & 3 \\
\hline 33 & Data scientist & Pakistan & 6 & 3 \\
\hline 34 & Software tester & Pakistan & 4 & 2 \\
\hline 35 & Software developer & Pakistan & 5 & 4 \\
\hline 36 & Software developer & Pakistan & 5 & 5 \\
\hline 37 & Lecturer & Pakistan & 6 & 3 \\
\hline 38 & Senior web developer & Pakistan & 8 & 6 \\
\hline 39 & Software engineer & Pakistan & 6 & 5 \\
\hline 40 & IT incharge & Pakistan & 8 & 5 \\
\hline 41 & Team lead & Pakistan & 7 & 5 \\
\hline 42 & Software developer & Pakistan & 3 & 3 \\
\hline 43 & Software quality assurance engineer & Pakistan & 5 & 4 \\
\hline 44 & Software developer & Pakistan & 5 & 5 \\
\hline 45 & Software developer & Pakistan & 4 & 3 \\
\hline 46 & Software engineer & Pakistan & 6 & 5 \\
\hline 47 & Web developer & Pakistan & 5 & 4 \\
\hline 48 & Web developer & Pakistan & 4 & 4 \\
\hline 49 & Web developer & Pakistan & 6 & 3 \\
\hline
\end{tabular}

However, for the normalization of Table 7 and also to determine the priority weight as shown in Table 8 , we followed the procedure described in Section 4.2.4. Each motivator's normalized value is determined by dividing its value by the total sum of its respective column values. Similarly, each motivator's priority weight value is determined by averaging the normalized values in its respective row. For example, Table 8 demonstrates that M17 is the most important motivator in the organization management category as it has highest importance compared to other motivators in the same category. Furthermore, M4 is the least effective motivator due to its low priority weight value. For determining the priority weight values of the motivators in other categories (Tables 10, 12,14 , and 16), we use the same approach.

Based upon questionnaire survey given in Figures 6-9, experts having agile practices and experience have provided pairwise judgments for the categories shown in Tables 7, 9, 11 , and 13. 


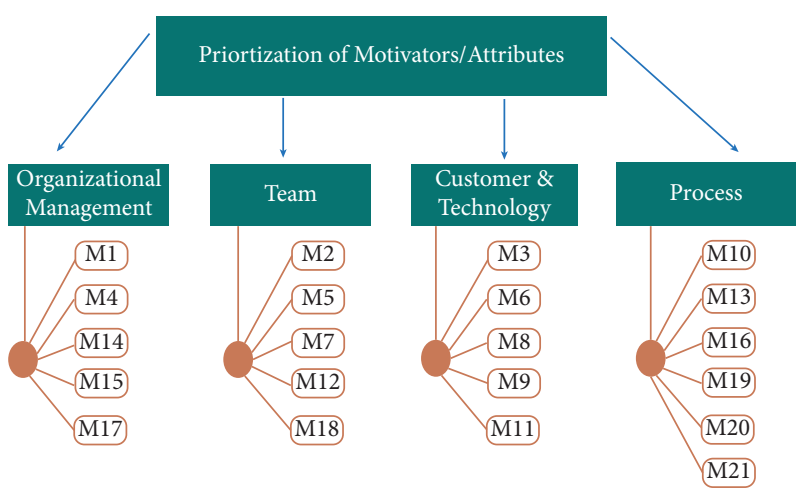

FIGURE 4: Categorization and mapping of motivators.

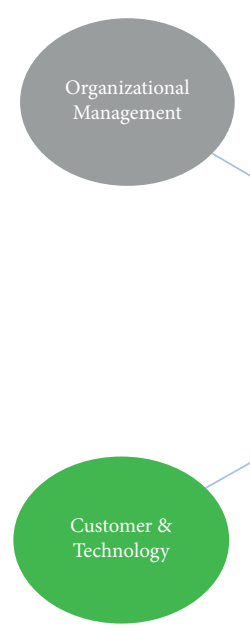

$\triangle$ Strong executive support Dedicated Management $\checkmark$ Risk Management

$>$ Knowledge sharing management

Mechanism for change management
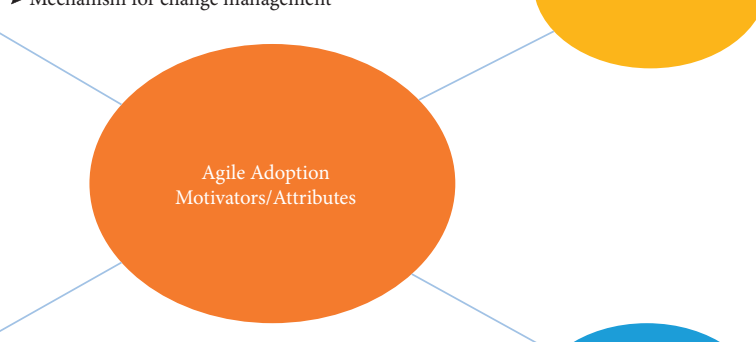

$>$ Face to face meetings

> Agile development environment

Strong collaboration with

$>$ Use of automated software tools
Sustainable planning

ion and communication

Quality production using pair programming

Training and learning and briefing of top management on agile

Requirements management using agile-oriented requirement

management process

Figure 5: Hierarchical structure of motivators.

TABLe 7: Pairwise matrix for category of "organization management."

\begin{tabular}{lccccc}
\hline S. no. & M1 & M4 & M14 & M15 & M17 \\
\hline M1 & 1 & 5 & $1 / 3$ & $1 / 3$ & $1 / 5$ \\
M4 & $1 / 5$ & 1 & $1 / 5$ & 3 & $1 / 7$ \\
M14 & 3 & 5 & 1 & 1 & $1 / 3$ \\
M15 & 3 & 5 & $1 / 3$ & 3 & $1 / 3$ \\
M17 & 5 & 7 & 3 & 1 \\
\hline
\end{tabular}

TABle 8: Normalized matrix for category of "organization management."

\begin{tabular}{|c|c|c|c|c|c|c|}
\hline S. no. & M1 & M4 & M14 & M15 & M17 & Priority weight \\
\hline M1 & 1 & 5 & 0.33 & 0.33 & 0.2 & 0.09 \\
\hline M4 & 0.2 & 1 & 0.2 & 0.2 & 0.14 & 0.04 \\
\hline M14 & 3 & 5 & 1 & 3 & 0.33 & 0.25 \\
\hline M15 & 3 & 5 & 0.33 & 1 & 0.33 & 0.16 \\
\hline M17 & 5 & 7 & 3 & 3 & 1 & 0.46 \\
\hline Total & 12.2 & 23 & 4.86 & 7.53 & 2 & 1 \\
\hline
\end{tabular}

The priority weight represents the local weight of each motivator after normalization, while the total represents the sum of all values in respective column.

The weighted value $(W)$ of each motivator is computed by averaging the normalized values of its respective row illustrated in Tables $8,10,12$, and 14 .

Hence, $\quad \lambda_{\max }=(12.2 \times 0.09)+(23 \times 0.04)+(4.87 \times 0.25)$ $+(7.53 \times 0.16)+(2 \times 0.46)=5.3603$, consistency index$=0.090$, random index $=1.12$, consistency ratio $=0.08<0.1$.
Based upon questionnaire survey given in Figure 10, experts having agile practices and experience in organization have provided pairwise judgments for four categories, i.e., "organization management," "team," "customer and technology," and "process," as shown in Table 15. 
TABLE 9: Pairwise matrix for category of "team."

\begin{tabular}{lccccc}
\hline S. no. & M2 & M5 & M7 & M12 & M18 \\
\hline M2 & 1 & $1 / 9$ & $1 / 5$ & $1 / 5$ & $1 / 2$ \\
M5 & 9 & 1 & 5 & $1 / 3$ & $1 / 7$ \\
M7 & 5 & $1 / 5$ & 1 & 1 & $1 / 3$ \\
M12 & 5 & 2 & 3 & 3 & $1 / 5$ \\
M18 & 7 & 3 & 5 & $1 / 3$ \\
\hline
\end{tabular}

TABLE 10: Normalized matrix for category of "team."

\begin{tabular}{lcccccc}
\hline S. no. & M2 & M5 & M7 & M12 & M18 & Priority weight \\
\hline M2 & 1 & 0.11 & 0.2 & 0.2 & 0.14 & $\mathbf{0 . 0 3}$ \\
M5 & 9 & 1 & 5 & 0.5 & 0.33 & 0.2 \\
M7 & 5 & 0.2 & 1 & 0.33 & 0.08 & $\mathbf{0 . 2 1}$ \\
M12 & 5 & 2 & 3 & 3 & 1 & $\mathbf{0 . 2 2}$ \\
M18 & 7 & 3 & 5 & $\mathbf{0 . 4 5}$ & $\mathbf{1}$ \\
Total & $\mathbf{2 7}$ & $\mathbf{6 . 3 1}$ & $\mathbf{1 4 . 2}$ & $\mathbf{2 . 0 3}$ & $\mathbf{1}$ \\
\hline
\end{tabular}

Note. $\quad \lambda_{\max }=(27 \times 0.03)+(6.31 \times 0.21)+(14.2 \times 0.08)+(5.03 \times 0.22)+(2 \times 0.45)=5.2777$, consistency index $=0.069$, random index $=1.12$, consistency ratio $=0.061<0.1$. The priority weight represents the local weight of each motivator after normalization, while the total represents the sum of all values in respective column.

TABLE 11: Pairwise matrix for category of "customer and technology."

\begin{tabular}{lccccc}
\hline S. no. & M3 & M6 & M8 & M9 & M11 \\
\hline M3 & 1 & $1 / 3$ & $1 / 9$ & $1 / 9$ & $1 / 3$ \\
M6 & 3 & 1 & $1 / 5$ & 1 & 5 \\
M8 & 9 & 5 & 1 & 1 & 4 \\
M9 & 9 & 3 & 1 & $1 / 5$ \\
M11 & 7 & $1 / 5$ & $1 / 4$ & $1 / 5$ \\
\hline
\end{tabular}

Note. $\lambda_{\max }=(29 \times 0.03)+(9.53 \times 0.14)+(2.56 \times 0.39)+(2.64 \times 0.37)+(15.1 \times 0.08)=5.3874$, consistency index $=0.096$, random index $=1.12$, consistency ratio $=0.085<0.1$.

TABLE 12: Normalized matrix for category of "customer and technology."

\begin{tabular}{|c|c|c|c|c|c|c|}
\hline S. no. & M3 & M6 & M8 & M9 & M11 & Priority weight \\
\hline M3 & 1 & 0.33 & 0.11 & 0.11 & 0.14 & 0.03 \\
\hline M6 & 3 & 1 & 0.2 & 0.33 & 5 & 0.14 \\
\hline M8 & 9 & 5 & 1 & 1 & 4 & 0.39 \\
\hline M9 & 9 & 3 & 1 & 1 & 5 & 0.37 \\
\hline M11 & 7 & 0.2 & 0.25 & 0.2 & 1 & 0.08 \\
\hline Total & 29 & 9.53 & 2.56 & 2.64 & 15.1 & 1 \\
\hline
\end{tabular}

The priority weight represents the local weight of each motivator after normalization, while the total represents the sum of all values in respective column.

TABle 13: Pairwise matrix for category of "process."

\begin{tabular}{lcccccc}
\hline S. no. & M10 & M13 & M16 & M19 & M20 \\
\hline M10 & 1 & 7 & 3 & $1 / 2$ & $1 / 3$ & M21 \\
M13 & $1 / 7$ & 1 & 3 & $1 / 4$ & $1 / 3$ & $1 / 9$ \\
M16 & $1 / 3$ & $1 / 3$ & 1 & $1 / 3$ & 2 & $1 / 9$ \\
M19 & 2 & 4 & 3 & 1 & $1 / 3$ & $1 / 4$ \\
M20 & 3 & 3 & $1 / 2$ & 4 & $1 / 9$ \\
M21 & 9 & 9 & 9 & & & 1 \\
\hline
\end{tabular}

As the CR value is less than 0.1, it is an acceptable value, and consistency is satisfactory.

5.3.4. Step 4. Check Consistency. The level of consistency for the organization management category is determined in accordance with the criteria mentioned in Section 4.2.5.
Following is the mathematical calculation to find the value of consistency ratio.

$\sum A j=$ sum of column in matrix $[A]$ as can be seen in Table $8, \quad W=$ weight,$\quad \lambda_{\max }=(12.2 \times 0.09)+(23 \times 0.04)+$ $(4.87 \times 0.25)+(7.53 \times 0.16)+(2.01 \times 0.46)=5.349$, consistency index $=\lambda_{\max }-n / n-1=0.087$, random index $(\mathrm{RI})=$ 1.12 , consistency ratio $=\mathrm{CI}=0.078<0.1$. 
TABLE 14: Normalized matrix for category of "process."

\begin{tabular}{lccccccc}
\hline S. no. & M10 & M13 & M16 & M19 & M20 & M21 & Priority weight \\
\hline M10 & 1 & 7 & 3 & 0.5 & 0.33 & 0.11 & $\mathbf{0 . 0 9}$ \\
M13 & 0.14 & 1 & 3 & 0.25 & 0.33 & 0.11 & $\mathbf{0 . 0 4}$ \\
M16 & 0.33 & 0.33 & 1 & 0.33 & 2 & 0.11 & $\mathbf{0 . 0 5}$ \\
M19 & 2 & 4 & 3 & 1 & 3 & 0.25 & $\mathbf{0 . 1 7}$ \\
M20 & 3 & 3 & 0.5 & 0.33 & 1 & 0.11 & $\mathbf{0 . 0 8}$ \\
M21 & 9 & 9 & 9 & 4 & 9 & $\mathbf{0 . 5 7}$ \\
Total & $\mathbf{1 5 . 4}$ & $\mathbf{2 4 . 3}$ & $\mathbf{1 9 . 5}$ & $\mathbf{6 . 4 1}$ & $\mathbf{1 5 . 6}$ & $\mathbf{1 . 6 9}$ & $\mathbf{1}$ \\
\hline
\end{tabular}

Note. $\lambda_{\max }=(15.4 \times 0.09)+(24.3 \times 0.04)+(19.5 \times 0.05)+(6.41 \times 0.17)+(15.6 \times 0.08)+(1.69 \times 0.57)=6.612$, consistency index $=0.1224$, random index $=1.24$, consistency ratio $=0.098<0.1$. The priority weight represents the local weight of each motivator after normalization, while the total represents the sum of all values in respective column.

TABLE 15: Pairwise matrix for overall categories.

\begin{tabular}{lcccc}
\hline S. no. & Organization management & Team & Process & Customer and technology \\
\hline Organization management & 1 & 1 & $1 / 3$ & $1 / 6$ \\
Team & 1 & 1 & 2 & $1 / 6$ \\
Process & 3 & $1 / 2$ & 1 & $1 / 3$ \\
Customer and technology & 6 & 6 & 3 & 1 \\
\hline
\end{tabular}

Note. $\lambda_{\max }=(11 \times 0.09)+(8.5 \times 0.14)+(6.33 \times 0.16)+(1.65 \times 0.61)=4.1993$, consistency index $=0.066$, random index $=0.9$, consistency ratio $=0.07<0.1$.

TABLE 16: Normalized matrix for overall categories.

\begin{tabular}{lccccc}
\hline S. no. & Organization management & Team & Process & Customer and technology & Priority weight \\
\hline Organization management & 1 & 1 & 0.33 & 0.16 & 0.16 \\
Team & 1 & 1 & 2 & 0.33 & $\mathbf{0 . 0 9}$ \\
Process & 3 & 0.5 & 1 & 1 & $\mathbf{0 . 1 6}$ \\
Customer and technology & 6 & 6 & 3 & $\mathbf{0 . 6 1}$ \\
Total & $\mathbf{1 1}$ & $\mathbf{8 . 5}$ & $\mathbf{6 . 3 3}$ & $\mathbf{1 . 6 5}$ & $\mathbf{1}$ \\
\hline
\end{tabular}

The priority weight represents the local weight of each motivator after normalization, while the total represents the sum of all values in respective column.

TABLE 17: Final priority list of motivators.

\begin{tabular}{|c|c|c|c|c|c|c|}
\hline Categories & Weight & Motivator & Local weights & Local ranking & Global weights & Final priority \\
\hline \multirow{5}{*}{ Organization management } & \multirow{5}{*}{0.09} & M1 & 0.09 & 4 & 0.0081 & 18 \\
\hline & & M4 & 0.04 & 5 & 0.0036 & 21 \\
\hline & & M14 & 0.25 & 2 & 0.0225 & 13 \\
\hline & & M15 & 0.16 & 3 & 0.0144 & 15 \\
\hline & & M17 & 0.46 & 1 & 0.0414 & 8 \\
\hline \multirow{5}{*}{ Team } & \multirow{5}{*}{0.14} & M2 & 0.03 & 5 & 0.0042 & 20 \\
\hline & & M5 & 0.21 & 3 & 0.0294 & 11 \\
\hline & & M7 & 0.08 & 4 & 0.0112 & 17 \\
\hline & & M12 & 0.22 & 2 & 0.0308 & 9 \\
\hline & & M18 & 0.45 & 1 & 0.063 & 3 \\
\hline \multirow{6}{*}{ Process } & \multirow{6}{*}{0.61} & M10 & 0.09 & 3 & 0.0549 & 6 \\
\hline & & M13 & 0.04 & 6 & 0.0244 & 12 \\
\hline & & M16 & 0.05 & 5 & 0.0305 & 10 \\
\hline & & M19 & 0.17 & 2 & 0.1037 & 2 \\
\hline & & M20 & 0.08 & 4 & 0.0488 & 7 \\
\hline & & M21 & 0.57 & 1 & 0.3477 & 1 \\
\hline \multirow{5}{*}{ Customer and technology } & \multirow{5}{*}{0.16} & M3 & 0.03 & 5 & 0.0048 & 19 \\
\hline & & M6 & 0.14 & 3 & 0.0224 & 14 \\
\hline & & M8 & 0.39 & 1 & 0.0624 & 4 \\
\hline & & M9 & 0.37 & 2 & 0.0592 & 5 \\
\hline & & M11 & 0.08 & 4 & 0.0128 & 16 \\
\hline
\end{tabular}




\begin{tabular}{|c|c|c|c|c|c|c|c|c|c|c|c|c|c|c|c|c|c|c|}
\hline \multicolumn{19}{|c|}{$\begin{array}{l}\text { With respect to Organizational Management, } \\
\text { Using the scale from } 1 \text { to } 9 \text { (where } 9 \text { is extremely and } 1 \text { is equally important), } \\
\text { please indicate (X) the relative importance of options A (left column) to options B (right column). }\end{array}$} \\
\hline $\begin{array}{c}\text { A } \\
\text { Options }\end{array}$ & 줄 & 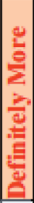 & 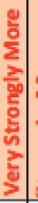 & 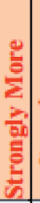 & & $\begin{array}{l}\frac{2}{2} \\
\frac{2}{2} \\
\frac{3}{3} \\
\frac{3}{3} \\
\frac{3}{3} \\
\frac{3}{3}\end{array}$ & $\frac{2}{\frac{7}{0}}$ & 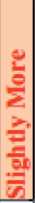 & 永 & 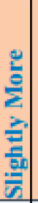 & 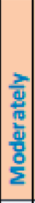 & 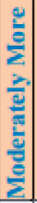 & 굴 & 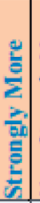 & 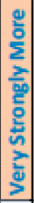 & 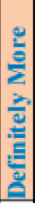 & 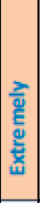 & $\begin{array}{c}\text { B } \\
\text { Options }\end{array}$ \\
\hline Strong executive support & 9 & 8 & 7 & 6 & 5 & 4 & 3 & 2 & 1 & 2 & 3 & 4 & 5 & 6 & 7 & 8 & 9 & Dedicated management \\
\hline Strong executive support & 9 & 8 & 7 & 6 & 5 & 4 & 3 & 2 & 1 & 2 & 3 & 4 & 5 & 6 & 7 & 8 & 9 & Risk management \\
\hline Strong executive support & 9 & 8 & 7 & 6 & 5 & 4 & 3 & 2 & 1 & 2 & 3 & 4 & 5 & 6 & 7 & 8 & 9 & $\begin{array}{l}\text { Knowledge sharing } \\
\text { management }\end{array}$ \\
\hline Strong executive support & 9 & 8 & 7 & 6 & 5 & 4 & 3 & 2 & 1 & 2 & 3 & 4 & 5 & 6 & 7 & 8 & 9 & $\begin{array}{l}\text { Mechanism for change } \\
\text { management }\end{array}$ \\
\hline Dedicated management & 9 & 8 & 7 & 6 & 5 & 4 & 3 & 2 & 1 & 2 & 3 & 4 & 5 & 6 & 7 & 8 & 9 & Risk management \\
\hline Dedicated management & 9 & 8 & 7 & 6 & 5 & 4 & 3 & 2 & 1 & 2 & 3 & 4 & 5 & 6 & 7 & 8 & 9 & $\begin{array}{l}\text { Knowledge sharing } \\
\text { management }\end{array}$ \\
\hline Dedicated management & 9 & 8 & 7 & 6 & 5 & 4 & 3 & 2 & 1 & 2 & 3 & 4 & 5 & 6 & 7 & 8 & 9 & $\begin{array}{l}\text { Mechanism for change } \\
\text { management }\end{array}$ \\
\hline Risk management & 9 & 8 & 7 & 6 & 5 & 4 & 3 & 2 & 1 & 2 & 3 & 4 & 5 & 6 & 7 & 8 & 9 & $\begin{array}{l}\text { Knowledge sharing } \\
\text { management }\end{array}$ \\
\hline Risk management & 9 & 8 & 7 & 6 & 5 & 4 & 3 & 2 & 1 & 2 & 3 & 4 & 5 & & 7 & 8 & 9 & $\begin{array}{l}\text { Mechanism for change } \\
\text { management }\end{array}$ \\
\hline $\begin{array}{l}\text { Knowledge sharing } \\
\text { management }\end{array}$ & 9 & 8 & 7 & 6 & 5 & 4 & 3 & 2 & 1 & 2 & 3 & 4 & 5 & 6 & 7 & 8 & 9 & $\begin{array}{l}\text { Mechanism for change } \\
\text { management }\end{array}$ \\
\hline
\end{tabular}

Figure 6: Pairwise comparison between motivators of "organizational management" category.

\begin{tabular}{|c|c|c|c|c|c|c|c|c|c|c|c|c|c|c|c|c|c|c|}
\hline \multicolumn{19}{|c|}{$\begin{array}{l}\text { With respect to Team, } \\
\text { Using the scale from } 1 \text { to } 9 \text { (where } 9 \text { is extremely and } 1 \text { is equally important), } \\
\text { please indicate }(X) \text { the relative importance of options A (left column) to options B (right column). }\end{array}$} \\
\hline $\begin{array}{c}\text { A } \\
\text { Options }\end{array}$ & 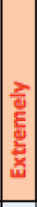 & 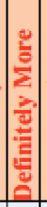 & 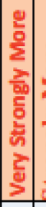 & 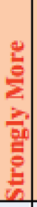 & ㄱ. & 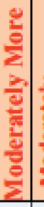 & $\begin{array}{l}\frac{2}{9} \\
\frac{2}{5} \\
\frac{5}{5} \\
\frac{0}{2} \\
\end{array}$ & 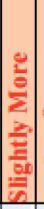 & 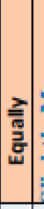 & 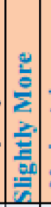 & 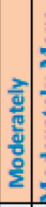 & 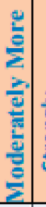 & 굴. & $\begin{array}{l} \\
\frac{2}{2} \\
\frac{2}{2} \\
\frac{2}{2} \\
\frac{1}{2} \\
\frac{1}{n}\end{array}$ & 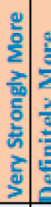 & 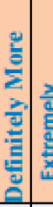 & 竞 & $\begin{array}{c}\text { B } \\
\text { Options }\end{array}$ \\
\hline $\begin{array}{l}\text { Cooperative organizational } \\
\text { culture }\end{array}$ & 9 & 8 & 7 & 6 & 5 & 4 & 3 & 2 & 1 & 2 & 3 & 4 & 5 & 6 & 78 & 8 & 9 & $\begin{array}{l}\text { Team competency agile- } \\
\text { development expertise }\end{array}$ \\
\hline $\begin{array}{l}\text { Cooperative organizational } \\
\text { culture }\end{array}$ & 9 & 8 & 7 & 6 & 5 & 4 & 3 & 2 & 1 & 2 & 3 & 4 & 5 & 67 & 78 & 8 & 9 & Team encouragement \\
\hline $\begin{array}{l}\text { Cooperative organizational } \\
\text { culture }\end{array}$ & 9 & 8 & 7 & 6 & 5 & 4 & 3 & 2 & 1 & 2 & 3 & 4 & 5 & 6 & 78 & 8 & 9 & $\begin{array}{l}\text { Scheduled trainings for } \\
\text { team members }\end{array}$ \\
\hline $\begin{array}{l}\text { Cooperative organizational } \\
\text { culture }\end{array}$ & 9 & 8 & 7 & 6 & 5 & 4 & 3 & 2 & 1 & 2 & 3 & 4 & 5 & 67 & 78 & 8 & 9 & $\begin{array}{l}\text { Leadership strong } \\
\text { commitment and team } \\
\text { autonomy }\end{array}$ \\
\hline $\begin{array}{l}\text { Team competency agile- } \\
\text { development expertise }\end{array}$ & 9 & 8 & 7 & 6 & 5 & 4 & 3 & 2 & 1 & 2 & 3 & 4 & 5 & 67 & 78 & 8 & 9 & Team encouragement \\
\hline $\begin{array}{l}\text { Team competency agile- } \\
\text { development expertise }\end{array}$ & 9 & 8 & 7 & 6 & 5 & 4 & 3 & 2 & 1 & 2 & 3 & 4 & 5 & $6 \mid 7$ & \begin{tabular}{l|l}
7 & 8
\end{tabular} & 8 & 9 & $\begin{array}{l}\text { Scheduled trainings for } \\
\text { team members }\end{array}$ \\
\hline $\begin{array}{l}\text { Team competency agile- } \\
\text { development expertise }\end{array}$ & 9 & 8 & 7 & 6 & 5 & 4 & 3 & 2 & 1 & 2 & 3 & 4 & 5 & 67 & 78 & 8 & 9 & $\begin{array}{l}\text { Leadership strong } \\
\text { commitment and team } \\
\text { autonomy }\end{array}$ \\
\hline Team encouragement & 9 & 8 & 7 & 6 & 5 & 4 & 3 & 2 & 1 & 2 & 3 & 4 & 5 & 67 & \begin{tabular}{l|l}
7 & 8
\end{tabular} & 8 & 9 & $\begin{array}{l}\text { Scheduled trainings for } \\
\text { team members }\end{array}$ \\
\hline Team encouragement & 9 & 8 & 7 & 6 & 5 & 4 & 3 & 2 & 1 & 23 & 3 & 4 & 5 & 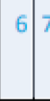 & 78 & 8 & 9 & $\begin{array}{l}\text { Leadership strong } \\
\text { commitment and team } \\
\text { autonomy }\end{array}$ \\
\hline $\begin{array}{l}\text { Scheduled trainings for } \\
\text { team members }\end{array}$ & 9 & 8 & 7 & 6 & 5 & 4 & 3 & 2 & 1 & 2 & 3 & 4 & 5 & 67 & 7 & 8 & 9 & $\begin{array}{l}\text { Leadership strong } \\
\text { commitment and team } \\
\text { autonomy }\end{array}$ \\
\hline
\end{tabular}

Figure 7: Pairwise comparison between motivators of "team" category. 


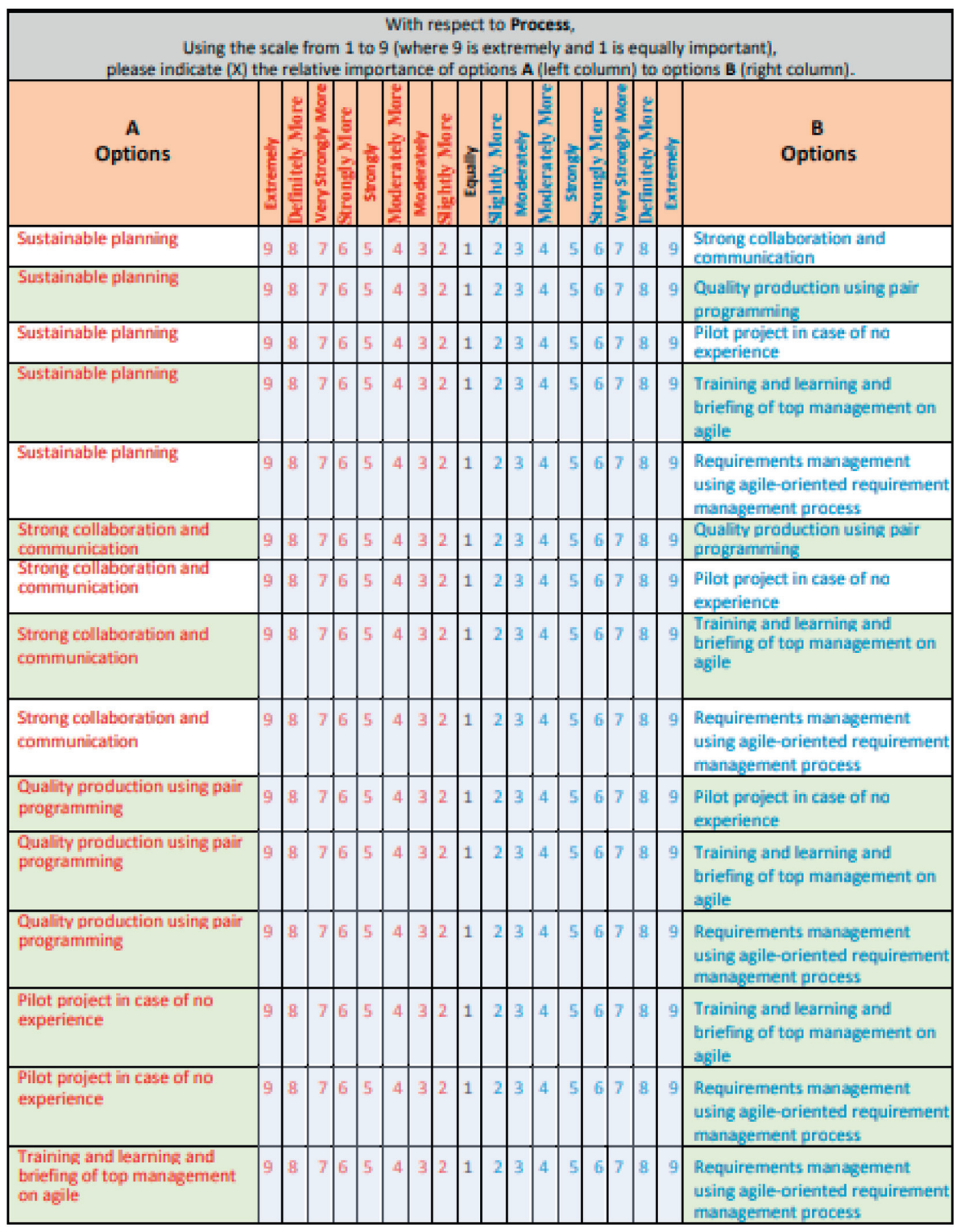

FIgURE 8: Pairwise comparison between motivators of "process" category.

As the CR value is less than 0.1 , it is an acceptable value, and consistency is satisfactory.

All of the motivators' categories, such as "team" (Tables 9 and 10), "customer and technology" (Tables 11 and 12), and "process" (Tables 13 and 14), and overall categories (Tables 15 and 16), are assessed using the same consistency check method.

5.3.5. Step 5. Calculate the Weights (Local and Global) and Final Prioritization of the Motivators. Table 17 demonstrates the final list of priority for agile adoption motivators, which is based on each motivator's global weight. Motivators having higher global weight values in all categories are considered of top priority. From a management perspective, the M21 is declared as the highest priority and most significant motivator for adopting agile, according to the summary results provided in Table 17. However, the results show that M4 is the least important motivator for adopting agile from management perspective. The ranking provided shows the extent to which motivators/attributes influence the adoption of agile methodology from a management perspective.

5.4. Results Discussion. The main aim of this research is to provide a prioritization framework for LSAD organizations to adopt these agile adoption motivators from management point of view based on AHP. The findings of the study will assist in the successful management of LSAD organization.

5.4.1. RQ1 (How Could the Identified Motivators Be Prioritized for Successful Management of Large-Scale Software Development Project Using AHP Approach?). The AHP method is used to rank the listed motivators and their groups in order of priority. The Analytical Hierarchy Process is a 


\begin{tabular}{|c|c|c|c|c|c|c|c|c|c|c|c|c|c|c|c|c|c|c|}
\hline \multicolumn{19}{|c|}{$\begin{array}{l}\text { With respect to Customer \& Technology, } \\
\text { Using the scale from } 1 \text { to } 9 \text { (where } 9 \text { is extremely and } 1 \text { is equally important), } \\
\text { please indicate (X) the relative importance of options A (left column) to options B (right column). }\end{array}$} \\
\hline $\begin{array}{c}\text { A } \\
\text { Options }\end{array}$ & 줄 & . & 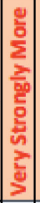 & 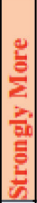 & 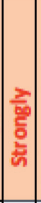 & $\mid \begin{array}{c}\frac{2}{3} \\
\frac{3}{2} \\
\frac{2}{3} \\
\frac{3}{2} \\
\frac{3}{3} \\
\frac{3}{2}\end{array}$ & 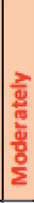 & 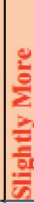 & $\frac{\underline{z}}{\frac{z}{3}}$ & 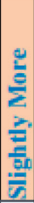 & 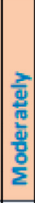 & 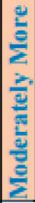 & 금 & 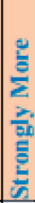 & 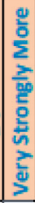 & 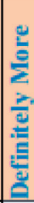 & 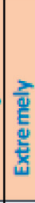 & $\begin{array}{c}\text { B } \\
\text { Options }\end{array}$ \\
\hline Face to face meetings & 9 & 8 & 7 & 6 & 5 & 4 & 3 & 2 & 1 & 2 & 3 & 4 & 5 & & 7 & 8 & 9 & $\begin{array}{l}\text { Agile development } \\
\text { environment }\end{array}$ \\
\hline Face to face meetings & 9 & 8 & 7 & 6 & 5 & 4 & 3 & 2 & 1 & 2 & 3 & 4 & 5 & 6 & 7 & 8 & 9 & Customer satisfaction \\
\hline Face to face meetings & 9 & 8 & 7 & 6 & 5 & 4 & 3 & 2 & 1 & 2 & 3 & 4 & 5 & & 7 & 8 & 9 & $\begin{array}{l}\text { Strong collaboration with } \\
\text { customer }\end{array}$ \\
\hline Face to face meetings & 9 & 8 & 7 & 6 & 5 & 4 & 3 & 2 & 1 & 2 & 3 & 4 & 5 & & 7 & 8 & 9 & $\begin{array}{l}\text { Use of automated } \\
\text { software tools }\end{array}$ \\
\hline $\begin{array}{l}\text { Agile devell } \\
\text { environme }\end{array}$ & 9 & 8 & 7 & 6 & 5 & 4 & 3 & 2 & 1 & 2 & 3 & 4 & 5 & & 7 & 8 & 9 & Customer satisfaction \\
\hline $\begin{array}{l}\text { Agile development } \\
\text { environment }\end{array}$ & 9 & 8 & 7 & 6 & 5 & 4 & 3 & 2 & 1 & 2 & 3 & 4 & 5 & & 7 & 8 & 9 & $\begin{array}{l}\text { Strong collaboration with } \\
\text { customer }\end{array}$ \\
\hline $\begin{array}{l}\text { Agile development } \\
\text { environment }\end{array}$ & 9 & 8 & 7 & 6 & 5 & 4 & 3 & 2 & 1 & 2 & 3 & 4 & 5 & & 7 & 8 & 9 & $\begin{array}{l}\text { Use of automated } \\
\text { software tools }\end{array}$ \\
\hline Customer satisfaction & 9 & 8 & 7 & 6 & 5 & 4 & 3 & 2 & 1 & 2 & 3 & 4 & 5 & & 7 & 8 & 9 & $\begin{array}{l}\text { Strong collaboration with } \\
\text { customer }\end{array}$ \\
\hline Customer satisfaction & 9 & 8 & 7 & 6 & 5 & 4 & 3 & 2 & 1 & 2 & 3 & 4 & 5 & & 7 & 8 & 9 & $\begin{array}{l}\text { Use of automated } \\
\text { software tools }\end{array}$ \\
\hline $\begin{array}{l}\text { Strong collaboration with } \\
\text { customer }\end{array}$ & 9 & 8 & 7 & 6 & 5 & 4 & 3 & 2 & 1 & 2 & 3 & 4 & 5 & & 7 & 8 & 9 & $\begin{array}{l}\text { Use of automated } \\
\text { software tools }\end{array}$ \\
\hline
\end{tabular}

Figure 9: Pairwise comparison between motivators of "customer \& technology" category.

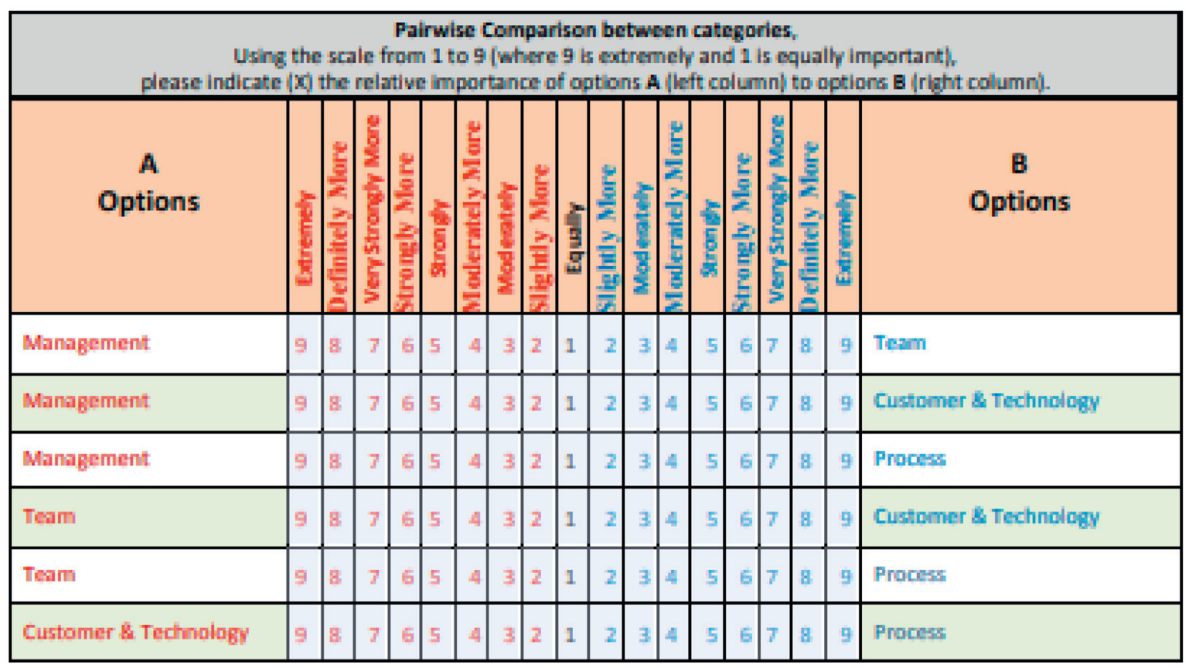

FIGURE 10: Pairwise comparison between categories of motivators.

well-known method for solving problems which involve complicated decision-making [36, 37], and we used this methodology to prioritize the motivators for large-scale agile development. Table 17 shows that M21 (requirements management using agile-oriented requirement management process) has the highest global weight (0.3477) and is considered the most important motivator, which clearly stated that experts recognized the need for agile-oriented requirement management process that could assist organizations to implement agile practices in an efficient way. The other top ranked motivators are M19 $(\mathrm{GW}=0.1037)$ and M18 $(\mathrm{GW}=0.063)$.
5.4.2. RQ2 (What Would Be the Taxonomy of the Identified Motivators That Could Assist towards the Successful Adoption of ASDM at Large-Scale Project?). Taxonomy of the listed motivators (Table 5) is established by grouping them into the four categories (Figure 4) and prioritizes them based on Analytical Hierarchy Process. This taxonomy aims at indicating the local weight that shows the priority of each motivator in each group, as well as the overall weight of each motivator that demonstrates its effect on the study's overall goal. The taxonomy offers a solid basis for researchers and practitioners to follow the LSAD based on their priorities. 


\section{Validation}

We applied AHP methodology to rank and prioritize agile adoption motivators based upon agile experts' judgment. The final results of this study revealed that the aforementioned agile adoption motivators are relevant to survey respondents work domain, which clarifies the precision of the chosen evaluation scale. In addition, the obtained results were further reviewed and validated by agile experts in other organizations who declared that these results are feasible for adoption in large-scale projects and teams.

\section{Conclusions and Future Work}

The importance of utilizing AHP methodology in various areas made us inspired to execute it for building up taxonomy of motivators for LSAD based on their prioritization. A list of 21 motivators is evaluated and categorized into four groups: "organization management," "team," "customer and technology," and "process."

Moreover, for prioritization of the motivators and their corresponding categories, an Analytical Hierarchy Process approach is used to evaluate motivator's priority based upon outcome of the second empirical survey performed with 49 agile specialists. The "process" is determined to be the most important category, according to the findings, and M21 (requirements management using agile-oriented requirement management process) and M19 (pilot project in case of no experience) are the key motivators of category "process." Hence, taxonomy of motivators and their respective categories has been developed, which provides a strong framework for LSAD organizations to evaluate and adapt them according to the priority.

The results of this analysis are both realistic and research-based. It offers a framework for LSAD organization having taxonomy of the agile adoption motivators from management perspective, based upon empirical research performed with the agile specialists who serve as a source of information for agile practitioners and researchers. The findings and analysis given may help industry experts in prioritizing motivation factors and categories before implementing them in an LSAD organization.

\section{Data Availability}

The data collected during the data collection phase are available from the corresponding author upon request.

\section{Conflicts of Interest}

The authors declare that they have no potential conflicts of interest.

\section{Acknowledgments}

This study was supported by the Fundamental Research Funds for Central University, no. 2462020YJRC001.

\section{References}

[1] K. Beck, M. Beedle, A. Van Bennekum et al., Manifesto for Agile Software Development, 2001.

[2] P. Serrador and J. K. Pinto, "Does agile work? - a quantitative analysis of agile project success," International Journal of Project Management, vol. 33, no. 5, pp. 1040-1051, 2015.

[3] M. F. Abrar, M. S. Khan, S. Ali et al., "Motivators for largescale agile adoption from management perspective: a systematic literature review," IEEE Access, vol. 7, pp. 2266022674, 2019.

[4] B. Boehm and R. Turner, "Management challenges to implementing agile processes in traditional development organizations," IEEE software, vol. 22, no. 5, pp. 30-39, 2005.

[5] D. K. Rigby, J. Sutherland, and A. Noble, "Agile at scale," Harvard Business Review, vol. 96, no. 3, pp. 88-96, 2018.

[6] T. Dyba and T. Dingsoyr, "What do we know about agile software development?" IEEE software, vol. 26, no. 5, pp. 6-9, 2009.

[7] T. Dingsøyr and N. B. Moe, Towards Principles of Large-Scale Agile DevelopmentSpringer, Berlin Germany, 2014.

[8] M. Paasivaara, B. Behm, C. Lassenius, and M. Hallikainen, "Towards rapid releases in large-scale xaas development at ericsson: a case study," in Proceedings of the IEEE 9th International Conference on Global Software Engineering, pp. 16-25, Shanghai, China, August 2014.

[9] M. Paasivaara, C. Lassenius, V. T. Heikkilä, K. Dikert, and C. Engblom, "Integrating global sites into the lean and agile transformation at ericsson," in Proceedings of the IEEE 8th International Conference on Global Software Engineering, pp. 134-143, Bari, Italy, August 2013.

[10] T. Dingsøyr, T. E. Fægri, and J. Itkonen, What Is Large in Large-Scale? A Taxonomy of Scale for Agile Software Development, pp. 273-276, Springer, Berlin, Germany, 2014.

[11] M. Paasivaara, S. Durasiewicz, and C. Lassenius, "Using scrum in a globally distributed project: a case study," Software Process: Improvement and Practice, vol. 13, no. 6, pp. 527-544, 2008.

[12] H. Berger and P. Beynon-Davies, "The utility of rapid application development in large-scale, complex projects," Information Systems Journal, vol. 19, no. 6, pp. 549-570, 2009.

[13] K. Petersen and C. Wohlin, "The effect of moving from a plandriven to an incremental software development approach with agile practices," Empirical Software Engineering, vol. 15, no. 6, pp. 654-693, 2010.

[14] E. Bjarnason, K. Wnuk, and B. Regnell, "A case study on benefits and side-effects of agile practices in large-scale requirements engineering," in Proceedings of the 1st Workshop on Agile Requirements Engineering, pp. 1-5, New York, NY, USA, July 2011.

[15] H. Koehnemann and M. Coats, "Experiences applying agile practices to large systems," in Proceedings of the IEEE Agile Conference, pp. 295-300, Chicago, IL, USA, Auguest 282009.

[16] A. Elshamy and A. Elssamadisy, Divide after You Conquer: An Agile Software Development Practice for Large Projects, pp. 164-168, Springer, Berlin Germany, 2006.

[17] S. Nerur, R. Mahapatra, and G. Mangalaraj, "Challenges of migrating to agile methodologies," Communications of the ACM, vol. 48, no. 5, pp. 72-78, 2005.

[18] S. C. Misra, V. Kumar, and U. Kumar, "Identifying some critical changes required in adopting agile practices in traditional software development projects," International 
Journal of Quality \& Reliability Management, vol. 27, no. 4, pp. 451-474, 2010.

[19] M. Cohn and D. Ford, "Introducing an agile process to an organization," Computer, vol. 36, no. 6, pp. 74-78, 2003.

[20] B. Boehm, "Get ready for agile methods, with care," Computer, vol. 35, no. 1, pp. 64-69, 2002.

[21] T. L. Saaty, The Analytic Hierarchy Process, McGraw-Hill, New York, NY, USA, 1980.

[22] M. J. Skibniewski and L. C. Chao, "Evaluation of advanced construction technology with AHP method," Journal of Construction Engineering and Management, vol. 118, no. 3, pp. 577-593, 1992.

[23] Z. Kremljak and C. Kafol, "Options, uncertainty and capability development," DAAAM International Scientific Book, pp. 75-87, 2012.

[24] S. A. Mian and C. X. Dai, "Decision-making over the project life cycle: an analytical hierarchy approach," Project Management Journal, vol. 30, no. 1, pp. 40-52, 1999.

[25] P. Rodriguez, J. Markkula, M. Oivo, and K. Turula, "Survey on agile and lean usage in finnish software industry," in empirical software engineering and measurement (ESEM)," in Proceedings of the 2012 ACM-IEEE International Symposium on, pp. 139-148, IEEE, Lund, Sweden, September 2012.

[26] M. F. Majeed, V. Esichaikul, and M. E. No, "Use of multiagent based platform for providing document-centric interoperability in the realm of E-government," in Proceedings of the in International Conference on Advances in Information Technology, pp. 141-149, Springer, Bangkok, Thailand, December 2013.

[27] M. Fowler and J. Highsmith, "The agile manifesto," Software Development, vol. 9, no. 8, pp. 28-35, 2001.

[28] A. M. M. Hamed and H. Abushama, "Popular agile approaches in software development: review and analysis," in Proceedings of the in International Conference on Computing, Electrical and Electronics Engineering (ICCEEE), pp. 160-166, IEEE, Khartoum, Sudan, Auguest 2013.

[29] T. Dyba and T. Dingsøyr, "Empirical studies of agile software development: a systematic review," Information and Software Technology, vol. 50, no. 9-10, pp. 833-859, 2008.

[30] J. A. Livermore, "Factors that significantly impact the implementation of an agile software development methodology," Journal of the Southwest, vol. 3, no. 4, pp. 31-36, 2008.

[31] M. Lindvall, D. Muthig, A. Dagnino et al., "Agile software development in large organizations," Computer, vol. 37, no. 12, pp. 26-34, 2004.

[32] H. U. Rahman, M. Raza, P. Afsar, A. Alharbi, S. Ahmad, and H. Alyami, "Multi-criteria decision making model for application maintenance offshoring using analytic hierarchy process," Applied Sciences, vol. 11, no. 18, p. 8550, 2021.

[33] M. A. Akbar, A. Ali Khan, A. Wahid khan, and S. Mahmood, "Requirement change management challenges in GSD: an analytical hierarchy process approach," Journal of Software: Evolution and Process, vol. 32, Article ID e2246, 2020.

[34] A. A. Khan and M. Shameem, "Multicriteria decision-making taxonomy for DevOps challenging factors using analytical hierarchy process," Journal of Software: Evolution and Process, vol. 32 , no. 10, 2020.

[35] B. Sayed, Z. Shamsi, and M. Sadiq, "A Method for the selection of agile methods using AHP," in Proceedings of the 5th International Conference on Frontiers in Intelligent Computing: Theory and Applications, Singapore, March 2017.

[36] J. K. W. Wong and H. Li, "Application of the analytic hierarchy process (AHP) in multi-criteria analysis of the selection of intelligent building systems," Building and Environment, vol. 43, no. 1, pp. 108-125, 2008.

[37] T. Yaghoobi, "Prioritizing key success factors of software projects using fuzzy AHP," Journal of Software: Evolution and process, vol. 30, no. 1, Article ID e1891, 2018.

[38] M. Shameem, R. R. Kumar, C. Kumar, B. Chandra, and A. A. Khan, "Prioritizing challenges of agile process in distributed software development environment using analytic hierarchy process," Journal of Software: Evolution and Process, vol. 30, no. 11, Article ID e1979, 2018.

[39] E. B. Sloane, M. Liberatore, R. Nydick, W. Luo, and Q. Chung, "Clinical engineering technology assessment decision support: a case study using the analytic hierarchy process (AHP)," in Proceedings of the Second Joint 24th Annual Conference and the Annual Fall Meeting of the Biomedical Engineering Society] [Engineering in Medicine and Biology, vol. 3, October 2002.

[40] I. Palcic and B. Lalic, "Analytical hierarchy process as a tool for selecting and evaluating projects," International Journal of Simulation Modelling, vol. 8, no. 1, 2009.

[41] L. I. Wen-Ying, "Application of ahp analysis in risk management of engineering projects," Journal of Beijing University of Chemical Technology (Natural Science Edition), vol. 1, pp. 46-48, 2009.

[42] basili, "The goal question metric approach," Encyclopedia of Software Engineering-2 Volume Set, pp. 528-532, Copyright by John Wiley \& Sons, Inc, Boca Raton, NJ, USA, 1994.

[43] M. Shameem, A. A. Khan, M. G. Hasan, and M. A. Akbar, "Analytic hierarchy process based prioritisation and taxonomy of success factors for scaling agile methods in global software development," IET Software, vol. 14, no. 4, pp. 389-401, 2020.

[44] T. L. Saaty, "Analytic hierarchy process," Encyclopedia of Operations Research and Management Science, Springer US, Boston, MA, USA, pp. 52-64, 2013.

[45] E. W. L. Cheng and H. Li, "Construction partnering process and associated critical success factors: quantitative investigation," Journal of Management in Engineering, vol. 18, no. 4, pp. 194-202, 2002. 